\title{
REVIEW ARTICLE Modeling anxiety in healthy humans: a key intermediate bridge between basic and clinical sciences
}

\author{
Christian Grillon ${ }^{1}$, Oliver J. Robinson ${ }^{2}$, Brian Cornwell ${ }^{3}$ and Monique Ernst ${ }^{1}$
}

\begin{abstract}
Animal models of anxiety disorders are important for elucidating neurobiological defense mechanisms. However, animal models are limited when it comes to understanding the more complex processes of anxiety that are unique to humans (e.g., worry) and to screen new treatments. In this review, we outline how the Experimental Psychopathology approach, based on experimental models of anxiety in healthy subjects, can mitigate these limitations and complement research in animals. Experimental psychopathology can bridge basic research in animals and clinical studies, as well as guide and constrain hypotheses about the nature of psychopathology, treatment mechanisms, and treatment targets. This review begins with a brief review of the strengths and limitations of animal models before discussing the need for human models of anxiety, which are especially necessary to probe higher-order cognitive processes. This can be accomplished by combining anxiety-induction procedures with tasks that probe clinically relevant processes to identify neurocircuits that are potentially altered by anxiety. The review then discusses the validity of experimental psychopathology and introduces a methodological approach consisting of five steps: (1) select anxiety-relevant cognitive or behavioral operations and associated tasks, (2) identify the underlying neurocircuits supporting these operations in healthy controls, 3) examine the impact of experimental anxiety on the targeted operations in healthy controls, (4) utilize findings from step 3 to generate hypotheses about neurocircuit dysfunction in anxious patients, and 5) evaluate treatment mechanisms and screen novel treatments. This is followed by two concrete illustrations of this approach and suggestions for future studies.
\end{abstract}

Neuropsychopharmacology (2019) 44:1999-2010; https://doi.org/10.1038/s41386-019-0445-1

\section{INTRODUCTION}

Anxiety [1] disorders are a major public health problem. They are the most frequent classes of mental disorders in Western societies, for which they are among the leading cause of disability [2] and come at huge individual and societal cost [3]. Anxiety is also comorbid with a variety of medical conditions, exacerbating symptoms, hampering recovery, and increasing the risk for other mental disorders, such as alcoholism and depression. Even when anxiety symptoms do not reach the criteria for a disorder, they can cause misery and poor health [3].

Unfortunately, our understanding of anxiety symptoms remains limited, and the treatment of anxiety disorders represents a significant challenge to mental health $[4,5]$. Current drug treatments often have suboptimal efficacy as well as unwanted side effects [5]. This situation reflects the difficulty of translational research, which has struggled to capitalize on the array of new technologies to develop efficient treatments. It also points, to some extent, to the practical challenge of developing animal models of mental disorders [6]. While animal models of anxiety provide critical insights into basic defense-survival mechanisms [4], promising novel treatments derived from animal models too often end up being ineffective in humans, and none of them have led to significant improvements to the current armamentarium of anxiolytic drugs, which has been stagnant for several decades [7]. This lack of effectiveness has prompted the pharmaco-industry to close or downsize research on mental illnesses [8]. Ultimately, this grim picture signals the need for a new approach to translational research to improve the synergy between basic science and clinical science.

In this paper, we argue that experimental models of anxiety in nonclinical, unmedicated humans can revitalize treatment discovery. The "experimental psychopathology" approach can bridge basic research in animals and clinical studies, as well as guide and constrain hypotheses about the nature of psychopathology, treatment mechanisms, and treatment targets $[9,10]$.

This paper focuses on experimental models of anxiety, as opposed to fear or stress. Of prime consideration when developing experimental models of psychopathology is the nature of symptoms. Fear and anxiety are different features of anxiety disorders [11], with a distinct underlying neurobiology [12]. Fear is a phasic response to a well-defined and identifiable proximal threat, whereas anxiety is a more sustained aversive state generated by uncertain future threat $[11,13]$. Fear is above all a behavioral response that mobilizes the organism to act (fight or flight) in the face of a life-threatening situation. By contrast, anxiety is a feeling of apprehension, a perceived sense of unpredictability, and aversive anticipation [13, 14]. While great progress has been made to elucidate the neurobiology of fear, thanks to robust translational experimental models, such as Pavlovian fear conditioning, comparatively much less is known about anxiety, partly because of the difficulty in modeling its symptoms in animals. More than fear, anxiety involves complex

\footnotetext{
${ }^{1}$ Section on the Neurobiology of Fear and Anxiety, National Institute of Mental Health, Bethesda, MD, USA; ${ }^{2}$ University College London, Institute of Cognitive Neuroscience, London, UK and ${ }^{3}$ Centre for Mental Health, Faculty of Health, Arts and Design, Swinburne University of Technology, Hawthorn, VIC, Australia Correspondence: Christian Grillon (christian.grillon@nih.gov)
} 
cognitive and executive processes mediated by high-order brain neurocircuits that are strikingly more developed in humans than animals, limiting the usefulness of animal models. Psychosocial stress also implicates complex cognitive processes. However, although the distinction between anxiety and psychosocial stress is not straightforward, there are important differences between these two emotional states. Experimentally, anxiety is usually induced by anticipation of an aversive event (e.g., shock [15]), whereas psychosocial stress is evoked by social-evaluative situations (e.g., Trier Social Stress Test [16], Montreal Imaging Stress Task [17]). Research on anxiety and stress focuses on different neurobiological mechanisms, limbic structures [4, 12], and the hypothalamic-pituitary-adrenal gland axis [18], respectively. Both anxiety paradigms and stress induce negative affective states, but anxiety differs from stress in terms of the specific physiological responses and psychological experience (e.g., hypervigilance and attention bias are specific to anxiety) [19], as well as hormonal changes (social stressors increase cortisol more robustly and reliably than anxiety-induction procedures). In addition, during psychosocial stress, the cognitive tasks themselves are used as stressors (the independent variable) and the dependent variables are the autonomic, hormonal, and neural responses. The underlying cognitive processes are not the focus of interest per se. This contrasts with studies that are designed to study the neurocognitive mechanisms that drive anxiety [20-25].

In this paper, we (1) briefly discuss the advantages and limitations of animal models and argue for the development of human models of anxiety, (2) present a rationale for the experimental psychopathology approach, (3) describe a neuroscience systems approach to experimental psychopathology in humans to investigate pathological anxiety and its treatments, (4) provide empirical illustrations of this approach, and finally (5) review issues that need to be addressed in future studies.

\section{ANIMAL AND HUMAN MODELS OF ANXIETY}

Experimental models and translational research are necessary to improve our understanding of anxiety, anxiety disorders, and their treatments. Of all the mental disorders, anxiety disorders are arguably most amenable to translation because, unlike many psychiatric symptoms, fear and anxiety are highly tractable in the laboratory. These defense-survival responses to threat can be readily induced and measured in animals and in humans, and their underlying neurocircuits are well-conserved across species [4, 12].

Why do we need to model anxiety in humans, given that (1) basic research in animal models on neurobiological mechanisms can go far beyond research in humans, and (2) clinical research comparing healthy controls with anxiety patients can identify variations from the norms? We argue that human models of anxiety are necessary for the same reasons we rely on animal models: to enhance basic knowledge and theories, define functional norms to help identify pathological mechanisms and treatment targets, and to screen new treatments. Animal and human models, however, have their own specific advantages, limitations, and can address distinct questions. They are complementary, but for progress to be made, their differing scopes, strengths, and weaknesses must be acknowledged.

Animal vs. human experimental models

The advantages of animal models over human models include the availability of more invasive experiments (but see ref. [26]) and of more advanced technical tools (e.g., optogenetic techniques). Research in animal models has advanced the characterization of functional neurocircuits and the underlying neurobiology, and the gene-to-phenotype relationship [27, 28]. Animal models are also essential at the early stages of drug development to establish safety, pharmacokinetics, and early evidence of target effectiveness [29].
However, animal models have also important limitations. They have failed to deliver clinically effective psychopharmacological treatments for anxiety disorders [30, 31] and have limited application to test novel treatments (e.g., mindfulness, neurostimulation). This poor predictive validity of clinical efficacy has multiple causes, including poor construct validity (e.g., in modeling subjective experiences) and the difficulty of modeling the cognitive and behavioral symptoms listed under the major classification systems (e.g., DSM-5) [26, 32]. As a result, the features of human anxiety modeled in animals can be fuzzy. In the defense of animal models, a key hurdle to their development is the current inadequate nosology of mental disorders based on phenomenology (i.e., patients' reports, signs) rather than the underlying biology, unknown pathogenic mechanisms, absence of biomarkers and recognized highly penetrant genetic variants, clinical heterogeneity, and sex differences in brain structures and functions $[6,22]$. In fact, animal models are expected to achieve greater validity and stronger clinical relevance, when the critical features of anxiety and anxiety disorders (biological markers, genetic makeup, and pathophysiology) will become better defined, and the exploration of the mechanisms of behavior in animals more sophisticated, owing to the remarkable advances in basic neuroscience tools and methods.

However, the one irreducible issue concerns the cognitive, emotional, and behavioral traits that are unique to humans [4]. While animal models have been instrumental in elucidating defense-survival mechanisms, these defense-survival mechanisms are only one component of a complex system that contributes to human anxiety. Basic defense mechanisms interact with higherorder cognitive and executive functions mediated by neocortical circuits that are uniquely developed in humans [33]. Above all, psychiatry is the field of medicine devoted to pathologies of the mind, which is the most complex and elusive faculty of the human being. The human mind harbors conscious and unconscious experiences and is the origin of conceptual abstraction and symbolic communication that cannot be assessed in animals $[4,26]$. In addition, the neural architecture of the brain is far more complex in humans than in animals, and anxiety disorders often reflect disturbance of evolutionary recent circuits. The neurocircuitry of anxious feelings, mental representations, and emotion regulation in humans implicates prefrontal areas, which are uniquely developed in humans. Many psychiatric symptoms (e.g., worries) cannot be convincingly evaluated in animals, and while some domains of functioning (abnormal social behavior, working memory, and attention control) can be modeled in animals, the analogy is only an approximation $[4,6]$.

Human models can address these limitations. Experimental models in humans provide insights into the core subjective, cognitive, and self-regulatory aspects of anxiety, which are responsible for functional impairment and bring patients to the clinic. Experimental psychopathology can characterize what is behaviorally and cognitively deviant from the norms in anxiety disorders. Human models are valuable tools to identify potential pathophysiological mechanisms and treatment targets [34-36]. Clearly, experimental psychopathology cannot achieve the detailed analysis of brain function that is possible in animal research. However, in coming years, improvement in neuroimaging techniques and computational psychiatry will enhance the yield of human research [37].

Human experimental models vs. clinical research

Human models of anxiety in healthy individuals can also inform and complement clinical research with patients. This is particularly important since research in patients is complex, costly, and challenging with regard to recruitment and confounding factors, such as comorbidity and drug treatment [38]. Fundamentally, experimental models in humans can test reciprocal causal and correlational effects of anxiety on cognition and executive 
functions [20]. They can also help disentangle the role of anxiety in other conditions that are often comorbid with anxiety (see ref. [22]).

Experimental models in healthy subjects also present an advantage of scale in that they can leverage the benefit of relatively easy recruitment of participants (relative to psychiatric patients) to speed up research and widen its scope for an in-depth investigation of the multiple faceted aspects of anxiety.

In addition, a most promising application of human models relates to treatment, providing some understanding on how treatments work [34, 39]. In addition, human models could be instrumental for screening novel anxiolytics [35, 36], adding specificity to the high sensitivity of animal models (see Step 5: treatment implications). Experimental psychopathology may also be an instructive first step to test non-pharmacological treatments that cannot be assessed in animals, such as cognitive and behavioral treatments (e.g., mindfulness) or neuromodulation [40].

Finally, because anxiety disorders are developmental brain disorders and because the manifestation of anxiety is different in children and in adults [41], experimental psychopathology affords the opportunity to implement a developmental perspective for anxiety research.

\section{EXPERIMENTAL PSYCHOPATHOLOGY: DEFINITION AND VALIDITY}

Experimental psychopathology is conducted in healthy individuals, and employs experimental models of psychopathology (e.g., anxiety) to gain insights into normal and abnormal behaviors and their underlying neurobiological mechanisms $[42,43]$. The validity of experimental models of anxiety in healthy humans is consistent with the dimensional conceptualization of psychopathology [44, 45], which assumes a continuum from normal to pathological anxiety, and therefore a similar continuity for the underlying mechanisms. While the conceptualization of anxiety disorders in terms of dimensions or categories has long been debated $[46,47]$, the dimensional view is espoused by preclinical [48] and clinical research [45]. That anxiety disorders result from inappropriate activation or exaggeration of otherwise adaptive responses to threat provides the rationale behind the experimental psychopathology approach. The same anxiety system that is perturbed in anxiety disorders is also activated by anxiety challenges in normal individuals, albeit in less extreme, persistent, or incapacitating forms [24, 25, 49,50] (see also section 'Step 3: Studies of the interplay of anxiety and cognition in healthy subjects'). Fear-conditioning studies are a validation of this view. Indeed, many of the neural structures underlying normative fear mechanisms in healthy subjects have been implicated in pathological anxiety, especially symptoms that are fear-specific, such as response to phobic stimuli [51]. It follows that normative neuromechanisms of anxiety should provide a blueprint for the search of pathological mechanisms and drive hypotheses about neurocircuit dysfunction in pathological anxiety. However, while the experimental psychopathology approach is consistent with the dimensional view of anxiety, it remains a hypothesis, and as such, it is falsifiable. If it turns out that normative and pathological mechanisms differ, the dimensional view of psychopathology will have to be revisited.

\section{A RECIPE FOR EXPERIMENTAL PSYCHOPATHOLOGY RESEARCH ON ANXIETY}

Anxiety is multifaceted and cannot be expected to be recapitulated in a single model. Like animal models, the intent of human models is not to mimic the whole disease [6], but to develop specific tests of behavioral and psychological operations relevant to the symptoms and treatment of the target disorder. Findings informing how experimentally induced anxiety affects these operations help generate hypotheses about biomarkers and the underlying neurobiological dysfunction and narrow the search for treatment targets for the specific modeled symptoms.

While studies of fear-related defense mechanisms examine short-duration responses to threat cues (e.g., Pavlovian fear conditioning), studies focusing on anxiety examine sustained aversive states. Anxiety-induction procedures include situations such as anxiogenic pharmacological challenges (e.g., $7.5 \% \mathrm{CO}_{2}$, CCK4) [52-59], darkness [60-62], or threat of unpredictable aversive stimuli (e.g., shock) $[15,63,64]$. So far, most studies have investigated defensive mechanisms in idle subjects (i.e., subjects not involved in a complex task) and have enhanced our understanding of the clinical relevance of these anxiety states [65-72] and their underlying neurobiology [53, 73-83].

However, this type of investigation of sustained anxiety, which focuses uniquely on emotional expression, is limited in scope and does not fully capitalize on the advantages of experimental models in humans. Indeed, the cognitive aspects of anxiety state are for the most part ignored. This lapse is an issue since emotional and cognitive processes are not organized separately, but contribute jointly to ongoing behavior [84], and subjective experience relies on cognitive processes such as attention and working memory [85]. In addition, cognitive formulations of anxiety provide elaborated theoretical models of psychopathology [86-89] and define the processes targeted by successful cognitive therapies. These theories emphasize the role of information processing (i.e., cognition) in the etiology and maintenance of anxiety disorders. In overanxious individuals, faulty perception, encoding, storage, retrieval, interpretation, control, and action interfere with ongoing goals, while deficits in executive function impair self-regulation (emotion regulation) [87, 90-93]. However, we currently have little mechanistic understanding of the impact of anxiety on these processes and their dysregulation in anxiety disorders. It is to study these cognitive processes that experimental psychopathology can be most beneficial. A better characterization of the dynamics between anxiety and cognition with the objective of identifying core cognitive processes that are vulnerable to anxiety could significantly improve our understanding of the pathological mechanisms.

Investigators have long used systems neuroscience to elucidate neurocircuits mediating behavioral plasticity and pharmacological effects [94]. This approach begins with the characterization of the functional neural architecture that mediates the behavior under scrutiny to subsequently identify where and how plasticity occurs in response to experimental manipulations. The systems neuroscience approach has been used with great success to uncover the underlying mechanisms of simple defense responses to threat in animals [94, 95] and in humans [96]. We argue that this approach can be applied to investigate how anxiety affects complex perceptual, cognitive, and behavioral processes in experimental psychopathology studies in humans.

The overall strategy is to combine a primary cognitive or behavioral task with experimentally induced anxiety. Its implementation follows five steps:

(1) Select anxiety-relevant cognitive or behavioral operations (e.g., attention bias for threat) and tasks (e.g., dot probe) to probe these processes,

(2) Identify the underlying neurocircuits via connectivity/ activation nodes in healthy volunteers,

(3) Examine the impact of experimental anxiety on the targeted operations and the underlying neurocircuits in healthy volunteers,

(4) Utilize findings from step 3 to generate and constrain hypotheses about the mechanisms of pathophysiology and neurocircuit dysfunction in anxious patients, and 
(5) Finally, evaluate the mechanisms of treatment efficacy and screen putative anxiolytic treatments in healthy individuals exposed to experimental anxiety.

Step 1: functional behavioral and cognitive domains and markers of anxiety

The first step is to select anxiety-relevant psychological and behavioral processes or constructs. One productive approach is to base this selection on findings from clinical research, which compares patients with anxiety disorders with individuals without psychiatric disorders. These studies have identified cognitive, executive, behavioral, neurobiological, and electrophysiological abnormalities in anxiety patients. The results of these studies have generated important theoretical models and psychological constructs that underscore key cognitive, executive, and behavioral variables presumed to play a role in the origins and maintenance of anxiety disorders. These include negative bias in information processing [92, 97, 98], worry [99, 100], emotional dysregulation [101], behavioral inhibition [102], and avoidance [103]. There are several established tasks and measures to investigate these constructs. For example, information- processing biases can be evaluated using event-related potentials (ERPs) in response to sensory stimuli [104-106] or behavioral responses on cognitive tasks, such as the dot probe, visual search paradigms, and the Stroop test [92]. These tasks have enhanced our understanding of how anxiety captures attention, but they have also generated conflicting theories regarding the nature and the stage of information-processing deficits in anxiety [92]. Resolution of these conflicts can be facilitated with studies of experimental anxiety in healthy subjects.

Another promising and more systematic approach relies on the Research Domain Criteria (RdoC) project, which seeks to relate dysfunction of specific neurobiological systems to symptoms [45]. The RdoC is organized around fundamental functional constructs that are studied along the full range of variation, from normal to abnormal, across multiple units of analysis. These constructs are grouped into higher-level functional domains and are investigated using well-validated paradigms that have been selected by experts in the field. Using a RdoC approach, experimental psychopathology seeks to better understand how anxiety changes behavior-brain relationships, and then relates these changes to pathological anxiety. One could argue that anxiety spans several RDoC constructs, the "potential threat" construct of the negative valence systems, and various constructs of the cognitive systems, including attention, perception, cognitive control, and working memory. For example, attentional bias for threat falls into the cognitive system and the negative valence system. From a RDoC perspective, experimental psychopathology explores the interaction between the domains of potential threat and various cognitive system constructs. The RDoC represents a valuable framework for organizing experimental psychopathology research, as it provides the scientific rationale to select constructs and validated tasks to probe these constructs. However, the list of constructs is not exhaustive, and it could be worthwhile to identify additional anxiety-relevant cognitive constructs (e.g., affective decision-making) [107]. This could be accomplished by following the example of research on the negative symptoms of schizophrenia. The MATRICS (Measurement and Treatment Research to Improve Cognition in Schizophrenia) initiative was designed to develop a consensus cognitive battery to stimulate the development of new drugs that target cognitive deficits in schizophrenia [108]. A panel of experts was put together to identify the relevant cognitive domains and constructs and select a battery of cognitive tests relevant to schizophrenia. A similar approach would greatly benefit the study of the core cognitive symptoms of anxiety.
Step 2: normative mechanisms in healthy subjects

This step belongs to the domain of cognitive neuroscience, which seeks to understand the neurocircuits of cognitive processes. Step 2 of the experimental psychopathology approach consists of identifying, in healthy individuals, the neural circuits underlying the behavioral/cognitive constructs selected in step 1. Neuroimaging techniques are the basic tools to examine these questions. They include most commonly magnetic resonance imaging (MRI), but also magnetoencephalography (MEG), and less frequently positron emission tomography (PET). Whereas information can be gleaned from structural brain data, functional data provide more direct information about the cognitive processes, since they record changes in neural activity that co-occur with changes in behavior. Two basic measures are supplied by fMRI: regional activation and functional connectivity. Most of the analyses, up till now, are correlational in nature. For example, working memory is a cognitive construct which has been "associated" with activations within the dorsolateral prefrontal cortex and parietal cortex. These regional activations are interpreted as forming the neural circuit that supports working memory. Naturally, the same is true for the functional connectivity measure.

Extended efforts have been made to formulate mathematical algorithms that could generate causal models. Two complementary methods, Granger causality (G-causality [109]) and dynamic causal modeling [110] have been developed, but have not been extensively applied. The reasons for this include the many assumptions and requirements needed for their successful application, and their complexity. A more in-depth discussion of these techniques is outside the scope of this review but see ref. [111]. Computational models of behavioral and neural processes are also powerful approaches to understand the underlying mechanisms that drive anxiety pathology. The idea is to build mathematical models of normal and abnormal behaviors to identify the components that drive pathology [112]. More recently, the introduction of machine-learning tools, while large data sets become publicly available, may change the landscape of brain-behavior neuroscience research. For the perspective of this review, machine-learning tools offer the possibility of exploiting a large array of behavioral and neuroimaging variables to not only refine the understanding of neural circuits, but also discover novel mechanisms underlying specific behavioral processes.

Step 3: studies of the interplay of anxiety and cognition in healthy subjects

Once the behavioral/cognitive process (Step 1) and its underlying neurocircuits (Step 2) are delineated, Step 3 assesses the effect of experimentally induced anxiety on these factors. Step 3 is the critical step that determines the relevance of the cognitive construct and the associated neural circuit to anxiety. Promising results from this step are then followed up in steps 4 and 5 . However, negative results signal the end of this specific investigation. Step 3 is the stage of experimental psychopathology that departs from but is the link to clinical research. In Step 3, cognitive tasks and their behavioral and neural signatures are explored in healthy individuals in a control condition and under a condition of experimentally induced sustained anxiety. Anxietyrelated changes in cognitive performance and the underlying neural substrates are then hypothesized to be markers of anxiety in general, and are expected to be relevant to clinical anxiety, which is what steps 4 and 5 will test. Figure 1 illustrates a hypothetical scenario where a neurocircuit underlying response to a cognitive task is affected by induced anxiety in healthy individuals. A network of three structures $\left(\mathrm{ROI}_{1}, \mathrm{ROI}_{2}\right.$, and $\left.\mathrm{ROI}_{3}\right)$ is implicated functionally in the task. During an anxiety-induction procedure, another structure, $\mathrm{ROI}_{\mathrm{x}}$ is activated and alters connectivity in the network, between $\mathrm{ROI}_{1}$ and $\mathrm{ROI}_{2}$. These changes in neural activity and connectivity would be expected to be implicated in pathological anxiety. 


\section{Healthy subjects performing a cognitive task}
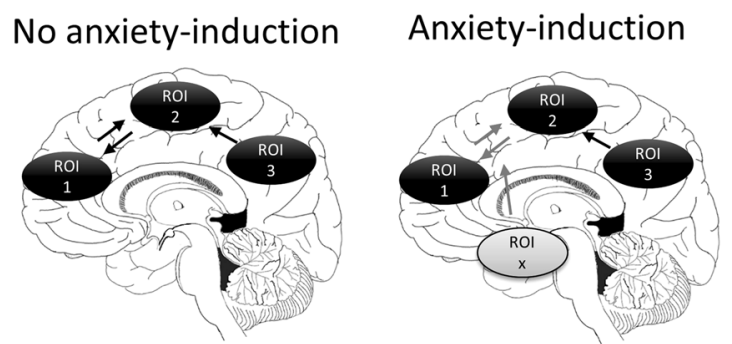

Fig. 1 Diagram illustrating the five-step experimental approach. Step 1: selection of a clinically relevant construct (e.g., attention bias for threat) and tasks (e.g., dot probe) that probe the construct; Step 2: characterization of the response (output) and the underlying neurobiology associated with the task (input) probing the construct in healthy subjects. The response can be a behavioral, cognitive, a pharmacological, or electrophysiological measure. The regions of interest $\mathrm{ROI}_{1}, \mathrm{ROI}_{2}$, and $\mathrm{ROI}_{3}$ represent three hypothetical structures that mediate the behavior tested by the task. The arrows represent hypothetical directional connectivity among these structures; Step 3: the task is combined with an anxiety-induction procedure to determine how anxiety affects the response and the underlying neurocircuits. In this example, a structure $\mathrm{ROI}_{x}$ affects the connectivity between $\mathrm{ROI}_{1}$ and $\mathrm{ROI}_{2}$. In Step 4, the task is tested in patients to determine whether the same processes and neurocircuits affected by experimental anxiety in healthy subjects are also implicated in the patients. Patients can be tested with or without an anxiety-induction procedure. Step 5: healthy subjects are tested as in Step 3 (task +induced anxiety) but are also given a treatment to examine the mechanisms of treatment responses or to screen putative anxiolytic treatments (do they affect the response and do they affect the same anxiety-neurocircuit identified in Step 2?)

Ultimately, the aim of experimentally induced anxiety is to uncover markers of anxiety that can lead to treatments. There has been a steady increase in studying the interplay of anxiety and cognition in recent years. The great majority of studies use the threat of unpredictable shocks [20, 21, 113-119] (also reviewed in ref. [120]) or 7.5\% $\mathrm{CO}_{2}$ inhalation [22-25]. The trend that emerges is that anxiety induced by threat of shock can not only have detrimental but also beneficial effects, depending on the nature of the task (reviewed in ref. [120]. Generally, threat of shock facilitates early sensory processing, the detection of threat information, and interference from distractors. It impairs short-term memory but facilitates long-term memory. It does not have a uniform effect on inhibitory control, impairing cognitive inhibition in emotional Stroop tests, while facilitating response inhibition in go-nogo tasks. Breathing $7.5 \% \mathrm{CO}_{2}$ increases the measures of hypervigilance, such as orienting and alerting $[24,25]$, and negative interpretation bias [121]. Overall, many of these effects mirror the effect of clinical anxiety on cognitive processes.

Therefore, the next step (Step 4) is to evaluate the use of these findings in healthy subjects as markers of clinical anxiety.

Step 4: mechanisms of pathophysiology

One objective of experimental psychopathology is to guide hypotheses about dysregulated cognitive processes and the underlying neurocircuits in pathological anxiety. The dimensional perspective of psychopathology predicts that pathological anxiety is associated with perturbations in some of the processes and neural mechanisms engaged by experimental anxiety. In the example we provide above (Fig. 1), one would hypothesize that the structure $\mathrm{ROI}_{\mathrm{x}}$ and the connectivity between $\mathrm{ROI}_{1}$ and $\mathrm{ROI}_{2}$ are potentially implicated in pathological anxiety.
What is the nature of the dysfunction that should be expected? From a dimensional perspective, the mechanisms that exacerbate responses to anxiety in healthy individuals should be amplified in anxiety patients (i.e., amplified excitatory mechanisms, and weakened inhibitory mechanisms). However, neuroadaptation following chronic anxiety may change the nature of these responses and the underlying neurocircuits over time. Consistent with this view, while studies generally show increased defensive reactivity and increased amygdala activity in pathological anxiety [72, 122], instances of hyporeactivity in patients are not infrequent $[123,124]$. The current interpretation of these opposing effects is that they reflect distinct symptoms. For example, while pathological anxiety tends to be associated with exaggerated defensive responses as measured with startle [66, 67], increased illness chronicity and comorbidity are associated with blunted reactivity [124]. A similar pattern of response has been reported at the neural level. In PTSD, for example, amygdala hyperreactivity is associated with hypervigilance and intrusive thoughts, whereas amygdala hyporeactivity leads to symptoms of dissociation and disengagement [123].

Another consideration concerns whether these maladaptive responses are triggered by specific events or whether they are chronically expressed. According to the diathesis-stress model of anxiety disorders, functional perturbation of these adaptive mechanisms should be the greatest during periods of anxiety or stress (e.g., during experimental threat). Alternatively, these mechanisms could be chronically and maladaptively engaged, even in the absence of experimental threat.

\section{Step 5: treatment implications}

Given the poor predictive validity of animal models, another promising clinical utilization of experimental psychopathology is treatment research. Although there is a dearth of research in this area, the two broad applications of experimental models in humans are to explore the mechanisms through which treatments exert their effect and to screen candidate anxiolytics in proof-ofconcept studies.

Treatment mechanisms. The mechanism by which conventional pharmacological treatments, such as the SSRIs and the benzodiazepines, or cognitive-behavioral therapy exert their effect is poorly understood. Experimental psychopathology is being used to clarify mechanisms responsible for the clinical efficacy of current pharmacological or psychological treatments. The results show that the effectiveness of SSRIs may be partly due to their downregulating effect on attentional bias for threat [34, 39]. Studies focused on defensive mechanisms indicate the benzodiazepine alprazolam and the SSRI citalopram, which are used to treat anxiety patients, reduce defense responses to unpredictable shock but not predictable shock in healthy subjects $[9,10]$. Interestingly, alcohol, which is used for its anxiety-dampening effect, also reduces defense responses to unpredictable but not predictable shock [125]. As research in humans and rodents points to distinct neurocircuits responsible for the response to predictable and unpredictable threat, these results provide clues as to the structures that may be preferentially implicated in these anxiolytic effects [12].

As expected, given the role of cognitive dysfunction in anxiety disorders, there is also evidence that conventional anxiolytics act on cognitive processes. Studies in healthy volunteers have shown that 7 days of treatment with the benzodiazepine diazepam or with the SSRI citalopram reduces a pattern of attentional vigilance to threat $[126,127]$. Because cognitive models suggest that anxiety disorders are associated with attentional biases for threat, these results suggest that the therapeutic action of classical anxiolytics may partly be mediated by normalizing these biases. 
Proof of concept. Anxiolytics that act preferentially through the $\mathrm{Y}^{-}$ aminobutyric acid (GABA) or serotoninergic systems have been the benchmark since the 1950 s and 1980 s, respectively. To improve the efficacy of anxiolytics, research has sought to discover new compounds that either target these systems or have a novel mode of action, for example, acting on the neuropeptide, glutamate, or endocannabinoid systems [31]. However, despite important breakthroughs in basic science that have led to the development of a multitude of drug anxiolytic candidates, the ability to bring to the marketplace efficient new compounds has not improved. The lack of success of drug development can be traced to the difficulties in selecting among the many candidate anxiolytic compounds, because of costly and time-consuming clinical trials, and the failure of animal models of anxiety to predict clinical efficacy. As long as candidate anxiolytics are safe, there is no reason why they could not be tested in models of anxiety, using healthy individuals to establish whether they are actually anxiolytic.

The predictive validity of a model refers the ability of the model to predict clinical efficacy. However, a model has predictive validity if it can successfully differentiate among effective and ineffective treatments. Animal models have a high level of sensitivity but poor specificity. The hope is that human models can add specificity and help drug sponsors make the "go-no-go" decision about novel compounds and choose appropriate treatment doses for subsequent clinical trials. Given their high cost and long duration, clinical trials are limited in the number of novel compounds that can be tested. New drug development methods, such as experimental models in humans, may facilitate and speed up screening, and improve the predictability and the efficacy of candidate anxiolytics.

Whether this approach will be successful remains to be seen. So far, the few studies that have tested putative anxiolytics in anxiety models in humans have had mixed success, as illustrated by translational research on antagonists of corticotropin-releasing factor (CRF) receptors. Based on strong preclinical evidence that CRF was a key mediator of stress-related responses, it has been suggested that drugs that target the $\mathrm{CRF}_{1}$ systems could be developed to relieve anxiety (as well as depression and alcoholism) [128]. $\mathrm{CRF}_{1}$ antagonists have proved to be anxiolytic in a wide range of animal models [129], but results in human models have not been as consistent. The $\mathrm{CRF}_{1}$ antagonists GSK876008 reduced startle potentiation in animal models of anxiety [130], but acute treatment with a similar CRF $_{1}$ antagonist, Verucerfont (GSK561679), did not reduce startle potentiation or subjective feeling of anxiety to unpredictable shock in a double-blind, crossover design in healthy subjects [35]. However, a 7-day treatment with another CRF antagonist (R317573), reduced subjective response but not physiological response to a $7.5 \% \mathrm{CO}_{2}$ inhalation challenge in a double-blind, randomized, placebo, and active controlled study [36]. These rather negative results should be considered in the light of clinical data that have shown the $\mathrm{CRF}_{1}$ antagonist to be clinically inefficient to treat generalized anxiety disorder, social anxiety disorders, depression, and comorbid anxiety-alcoholism [131, 132]. It is noteworthy that the same CRF $_{1}$ antagonist that was tested in the fear-potentiated startle model in humans [35], was also found to have no anxiolytic effect when given chronically in individuals with PTSD [133]. Although negative, these results have a positive side. The fear-potentiated startle model in humans did not produce a false positive: a clinically ineffective drug was ineffective in the human model.

Beside screening putative anxiolytics, human models will be necessary to evaluate non-pharmacologic treatments, such as exercise [134], cognitive-behavioral [135], mindfulness, or neuromodulation [40]. One advantage of experimental models in humans is that their sensitivity and specificity may be improved by targeting pathological mechanisms identified via the experimental psychopathology approach.

\section{EXAMPLES OF THE EXPERIMENTAL PSYCHOPATHOLOGY} APPROACH TO PRE-ATTENTIVE INFORMATION PROCESSING

Cognitive models emphasize the role of deficits in early information processing as a primary and persistent manifestation of pathological anxiety, contributing to symptoms of hypervigilance and downstream malfunction of more complex cognitive operations [92, 136, 137]. Various psychological constructs have been employed to study early information-processing deficits in pathological anxiety, including attentional bias [92], sensory gating [138, 139], and pre-attentive perceptual processing $[137,140-142]$. This section illustrates how experimental psychopathology can provide clues about neurocircuit dysfunction using two specific examples: 1) perceptual sensitivity and 2) negative biases.

\section{Perceptual sensitivity}

Step 1: functional domains and markers of anxiety: mismatch negativity. Effective early detection of environmental change is adaptive, as it provides for rapid orienting to potential threats, driving the organism to adopt cautious behavioral strategies [143]. Early perceptual responding to environmental changes can be examined with oddball stimulus paradigms. These paradigms assess how the organism responds to rare, deviant stimuli. A consistent electroencephalographic response to these unexpected stimuli has been identified and labeled mismatch negativity (MMN). In other words, the MMN is a brain-evoked potential in response to stimuli that deviate (prediction errors) from an established familiar sequence of sensory stimuli (e.g., change in tone frequency) [144]. It is considered a measure of pre-attentive detection because it can be elicited when attention is focused elsewhere [145].

As a measure of sensory perception and auditory discrimination, the $\mathrm{MMN}$ provides a window into the state of vigilance of the brain $[146,147]$. Consistent with this view, the MMN is abnormally elevated in a number of anxiety-related disorders, including PTSD [140, 141], panic disorder [142], and phobia [148]. These findings support brain's heightened sensitivity to environmental changes in these patient populations (i.e., hypervigilance). Heightened MMN is also associated with behavioral inhibition, a temperamental vulnerability for later anxiety disorders [149]. These results indicate that the MMN can be used as a proximal measure of anxious hypervigilance to gain insights into the underlying neurocircuit dysfunction.

Step 2: normative mechanisms in healthy subjects. While the neural regions contributing to MMN generation have long been elucidated [150], more recent works relying on dynamic causal modeling (DCM) have provided a mechanistic understanding of how the magnetoencephalographic MMN (MMNm) is generated [151]. The $M M N m$ is generated within a well-established frontotemporal network composed of bilateral sources over the primary and secondary auditory cortex (superior temporal gyrus, STG), and inferior frontal gyri (IFG) [151] (Fig. 2, left). DCM shows that the MMN can be explained by changes in the strength of the connectivity between (extrinsic) and within (intrinsic) these cortical sources (Fig. 2, right) [151]. Forward connections can be conceptualized as bottom-up processes transmitting sensory information from $A 1$ to higher cortical levels and convey prediction errors (MMN). Backward connections represent top-down predictions based on prior sensory experience and explain away prediction errors (deviance detection).

Step 3: studies of the interplay of anxiety and cognition. Consistent with the dimensional view of psychopathology, the MMNm is also increased by experimental anxiety in healthy subjects [104, 105]. The underlying mechanisms responsible for this increase have been recently elucidated via DCM and involve a rebalance of forward and backward connections. Threat of shock enhances 

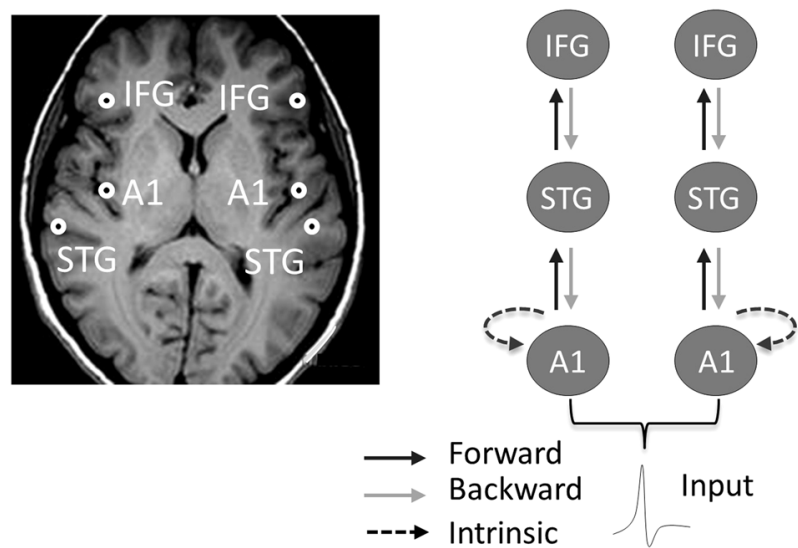

Fig. 2 Left. The MMNm arises from bilateral sources over primary secondary auditory cortex (superior temporal gyrus, STG), and inferior frontal gyri (IFG) [150]. Right. Dynamic causal modeling shows that the MMN results from changes within and among these cortical sources [151]. Forward connections can be conceptualized as bottom-up processes transmitting sensory information from A1 to higher cortical levels and convey prediction errors (MMN). Backward connections represent top-down predictions based on prior sensory experience and explain away prediction errors (deviance detection). In the safe context, the MMN is mediated by changes in both extrinsic feedforward and feedback connectivity, as well as intrinsic connectivity (not shown). Anxiety induced by threat of shock suppresses feedback connectivity. The anxiolytic alprazolam reestablishes feedback connectivity (not shown)

postsynaptic gain in the primary auditory cortex and modulation of the feedforward pathway, but attenuates the normal feedback signaling, which results in a failure to attenuate the ascending prediction errors [104]. These results suggest that anxiety-induced hypervigilance results from heightened sensitivity of bottom-up processes and failure of top-down modulation.

Having established via DCM that the changes within the MMNm neurocircuit are responsible for the increased MMNm by anxiety, the next step will be to identify the structure(s) that cause(s) these changes. One potential structure is the amygdala. The amygdala plays a critical role in threat evaluation [152], boosts processing [153], is involved in novelty detection [154, 155], and importantly, is activated by stimulus deviance in a time window that corresponds to IFG activation [105].

Step 4: mechanisms of pathophysiology. The results of experimental psychopathology constrain the search for the perturbation underlying the increased MMN in anxiety pathology. The identification of the normative mechanisms responsible for the increased MMN by anxiety leads to the hypotheses that comparable changes in the balance between feedforward and feedback signaling caused by threat of shock in healthy subjects are also responsible for the increased MMN in anxiety pathology. This hypothesis has not yet been tested.

Step 5: treatment implications. Drugs acting on gammaaminobutyric acid receptors can downregulate and upregulate hypervigilance $[156,157]$ and decrease or increase the MMN [158-160], respectively. In healthy subjects, the benzodiazepine alprazolam attenuates the threat-modulated $\mathrm{MMNm}$ and reestablishes the normal balance between feedforward and feedback signaling [104]. This suggests that benzodiazepines may reduce hypervigilance, partly by dampening early deviance detection. These results suggest that treatment aimed at reducing hypervigilance symptoms in pathological anxiety should target the balance between feedforward and feedback implicated in deviance detection.
Negative biases

Step 1: functional domains and markers of anxiety: attention bias. Attention bias for threatening stimuli has long been associated with pathological anxiety [92]. It reflects the propensity to rapidly detect and react to threat, and can be investigated using a wide range of tests, which reflect different aspects of attention, including the dot probe, the emotional Stroop, and emotional face processing $[92,120,161]$. A face-processing task is the exemplar selected here.

Step 2: normative mechanisms in healthy subjects. Neural models of emotion amplification and emotion regulation suggest several neural signals implicated in attention bias for threat. The amygdala automatically detects salient environmental stimuli $[162,163]$. Response flexibility is associated with structures that amplify the threat signals, such as the rodent's prelimbic cortex or its putative human equivalent, the $\mathrm{dACC} / \mathrm{dmPFC}$, and structures that protect goal-directed processing from threat distractors, including the ventromedial PFC (vmPFC), ventrolateral PFC (vIPFC), ACC, and IFG [164-166]. It is likely that some of these structures work together for adaptive behavior. Experimental models in humans have helped refine our understanding of functional connectivity among these structures to support bias attention in changing environments.

Step 3: studies of the interplay of anxiety and cognition. Studies in healthy subjects during induced anxiety have highlighted the role of cortical-subcortical connectivity in attention bias for threat. More specifically, in a series of studies using an emotional face identification task, it was first reported that induced anxiety drives attentional bias; subjects show quicker detection of fearful faces and greater defense response (i.e., as measured with startle) upon presentation of fearful faces during threat of shock compared with a safe condition $[161,167]$. It was then shown that this heightened attentional bias was associated with increased connectivity between the $\mathrm{dACC} / \mathrm{dmPFC}$ and the amygdala, providing evidence of an "aversive amplification circuit" that strengthens amygdala response to facilitate threat detection (Fig. 3) [168, 169]. In addition, the strength of this connectivity correlated positively with the behavioral bias index, suggesting that this circuit drives negative bias.

It has been argued that the dACC/dmPFC-amygdala neurocircuit serves to "prime" the amygdala, maintaining the amygdala in a state of readiness. This provides a mechanism by which the

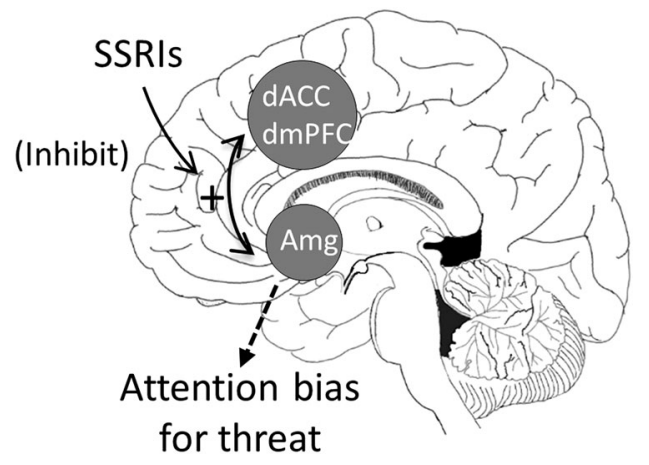

Fig. 3 Proposed model of attention bias for threat in anxiety. Increased bidirectional coupling between the dorsal anterior cingulate/dorsomedial prefrontal cortex (dACC/dmPFC) and amygdala (amg) promotes threat bias. Coupling is transiently activated during anxiety states in healthy controls, facilitating the detection of threat. However, the coupling is chronically engaged in pathological anxiety, leading to maladaptive threat bias. Lowering serotonin has a similar effect as induced anxiety: it increases dACC/dmPFC-amygdala coupling. By increasing serotonin, SSRIs may reduce attention bias for threat via inhibition of $d A C C / d m P F C$-amygdala coupling 
amygdala can detect and react rapidly to alerting and potentially dangerous stimuli during sustained anxiety states without maintaining a sustained level of activation [170].

Step 4: mechanisms of pathophysiology. Critically, it was subsequently found that the same $\mathrm{dACC} / \mathrm{dmPFC}$-amygdala neurocircuit is overactive in anxiety patients, in the absence of experimental anxiety (i.e., without threat of shock) [98]. In other words, the same neurocircuit responsible for threat bias, which is appropriately engaged and disengaged in healthy subjects by threat and safety, is chronically activated in anxious patients (i.e., in safe environments).

These studies validate the experimental psychopathology approach and further provide evidence that an otherwise selfprotective neurocircuit is dysfunctional in anxiety disorders. The positive correlation in healthy individuals between trait anxiety and the strength of the dACC/dmPFC-amygdala coupling [168] suggests that this neurocircuit indexes a vulnerability to anxiety disorders.

Step 5: treatment implications. The $\mathrm{dACC} / \mathrm{dmPFC}$-amygdala neurocircuit therefore represents a potential neural target for treatment. Neural markers are more proximal than behavioral markers, and as such, targeting the dACC/dmPFC-amygdala circuit may prove to be a powerful way of developing treatments.

Ideally, one would want to decrease dACC/dmPFC-amygdala coupling [98, 171]. The mechanism by which activity in this neurocircuit can be reduced is not fully understood, but evidence shows that serotonin plays a key role. Serotonin affects affective processing [172, 173] and the first line of psychopharmacological treatment for anxiety disorders, the SSRIs, alters serotonin neurotransmission [174]. In addition, amygdala response to fearful faces is modulated by a serotonin transporter polymorphism [175]. More direct evidence of serotonin involvement in $\mathrm{dACC} / \mathrm{dmPFC}$-amygdala coupling comes from findings that, in healthy subjects, reduced serotonin function following depletion of its precursor, tryptophan increases the strength of the connectivity in this circuit [176]. These results suggest that SSRIs may reduce anxiety symptoms by increasing serotonin, which normalizes or reduces the excessive dACC/dmPFC-amygdala coupling responsible for promoting threat bias. This interpretation would be consistent with evidence that serotonin therapeutic effects are mediated by the serotoninergic reduction in attention bias [173, 177]. Figure 3 illustrates this possibility. Given that increased $\mathrm{dACC} / \mathrm{dmPFC}$-amygdala coupling promotes threat biases, and reducing serotonin increases $\mathrm{dACC} / \mathrm{dmPFC}$-amygdala, SSRIs may reduce threat biases by inhibiting $\mathrm{dACC} / \mathrm{dmPFC}$-amygdala

coupling. Interestingly, psychological treatments (e.g., cognitive-behavioral therapy) of anxiety disorders, which can be as effective as pharmacological treatment [178], may also work by disengaging this circuit [171].

\section{FUTURE DIRECTIONS}

Whether the experimental psychopathology approach will bring a new insight into psychopathology and will help screen novel treatments remains to be seen. Experimental psychopathology is still in its infancy, but recent progresses are encouraging, supporting further development of this approach to fully contribute to clinical research. Below, we briefly review of few issues that need to be addressed to take full advantage of experimental psychopathology:

1. Sex and developmental changes: Anxiety disorders are more prevalent in women [179] and girls experience more anxiety symptoms than boys. Experimental psychopathology can be applied to children and adolescents [180] and can contribute to elucidating the neural basis of this sex difference by characterizing developmental changes.

2. Interindividual differences: Response to anxiety-inducing procedures [181-184] and cognitive performance [185] vary among individuals, reflecting the influence of temperamental, genetic, or environmental factors. It is likely that the interaction of cognition and experimental anxiety, as well as the treatment effects on these interactions, are similarly affected by interindividual differences. It will be important to identify these factors, since they may critically influence the psychopathological mechanisms and treatment targets. By helping identify the interindividual characteristics that determine treatment effects, experimental psychopathology carries implications for personalized medicine [186].

3. Anxiety-induction procedures: Different classes of environmental threats activate different defense mechanisms. Defense responses to proximal vs. more distal or uncertain threats are distinguishable in terms of behavior, cognition, and neurobiological substrates [187], as well as psychopathology [11]. Similarly, the response to bodily harm differs from that of social threat $[188,189]$. Aversive stimuli, such as shocks, have been successfully used in experimental models in humans $[66,67,190]$. However, threat of shock may not be appropriate to model all symptoms of anxiety. For example, a low dose of $\mathrm{CO}_{2}$ (e.g., 7.5\%) challenge has been proposed as a model of general anxiety disorder [191]. Behavioral avoidance tasks, where subjects anticipate a feared situation (e.g., anticipation of public speaking in social anxiety) are also a promising tool [192]. For example, healthy controls and patients with social anxiety show distinct emotional responses and cognitive regulation to social threat compared with physical threat [189, 193], and avoidance performance in a virtual elevated plus-maze is associated with the symptom of acrophobia but not social anxiety or trait anxiety [194]. This approach can also be extended to more specific symptoms, such as emotional distraction by worries and intrusive thoughts [195]. Future works will need to examine the commonalities and differences in the effects of different types of anxietyinduction procedures on cognitive and behavioral performance and the underlying neurocircuits [196]. It will be important to determine the extent to which different anxiety-induction procedures model symptoms that are similar or vary across disorders.

4. Drug screening: One exciting potential application of experimental psychopathology is to generate proof-ofconcept evidence of the efficacy of novel psychopharmacological and psychological treatments [34, 35, 191]. Currently, determining the efficacy of a drug or psychological intervention requires expensive and time-consuming clinical trials in patients. Experimental psychopathology could provide optimization of this process, leading to a rapid and affordable indication of efficacy at an early stage of treatment development [30]. However, a question for future studies is the extent to which treatments that work on normative responses also work on pathological responses.

\section{CONCLUSION}

Animal models are essential to advance our understanding of anxiety, but their limitations are increasingly recognized. We have proposed a general framework centered on experimental psychopathology to improve research on pathological anxiety. Combining anxiety challenges with tasks that probe clinically relevant psychological or behavioral constructs to identify clinically relevant neurocircuits provides a new approach to translational research on pathological anxiety. 


\section{FUNDING AND DISCLOSURE}

This work was supported by the Intramural Research Program of the National Institute of Mental Health, project number ZIAMH002798 (clinical protocol 02-M-0321 (NCT00047853), 01-M0185 (NCT00026559)) to CG, grant numbers MR/K024280/1 and MR/K0240817/1 to OJR. OJR has completed consultancy work for IESO digital health and Brainbow and is running an Investigator Initiated Trial with Lundbeck. He holds an MRC Industrial Collaboration Award with Cambridge Cognition. The authors declare that they have no conflict of interest.

\section{ADDITIONAL INFORMATION}

Publisher's note: Springer Nature remains neutral with regard to jurisdictional claims in published maps and institutional affiliations.

\section{REFERENCES}

1. Stein MB, Craske MG. Treating Anxiety in 2017: optimizing care to improve outcomes. JAMA 2017;318:E1-E2.

2. Kessler RC, Chiu WT, Demler O, Merikangas KR, Walters EE. Prevalence, severity, and comorbidity of 12-month DSM-IV disorders in the National Comorbidity Survey Replication. Arch Gen Psychiatry 2005;62:617-27.

3. Chisholm D, Sweeny K, Sheehan P, Rasmussen B, Smit F, Cuijpers $P$, et al. Scaling-up treatment of depression and anxiety: a global return on investment analysis. Lancet Psychiatry 2016;3:415-24.

4. LeDoux JE, Pine DS. Using neuroscience to help understand fear and anxiety: a two-system framework. Am J Psychiatry 2016;173:1083-93.

5. Koen N, Stein DJ. Pharmacotherapy of anxiety disorders: a critical review. Dialog Clin Neurosci 2011;13:423-37.

6. Nestler EJ, Hyman SE. Animal models of neuropsychiatric disorders. Nat Neurosci 2010;13:1161-9.

7. Zoellner LA, Foa EB. Applying Research Domain Criteria (RDoC) to the study of fear and anxiety: a critical comment. Psychophysiol 2016;53:332-5.

8. Nutt D, Goodwin G. ECNP Summit on the future of CNS drug research in Europe 2011: report prepared for ECNP by David Nutt and Guy Goodwin. Eur Neuropsychopharmacol 2011;21:495-9.

9. Grillon C, Chavis C, Covington MS, Pine DS. Two-week treatment with citalopram reduces contextual anxiety but not cued fear. Neuropsychopharmacol 2009; 34:964-71.

10. Grillon C, Baas JMP, Pine DS, Lissek S, Lawley M, Ellis V, et al. The benzodiazepine alprazolam dissociates contextual fear from cued fear in humans as assessed by fear-potentiated startle. Biol Psychiatry 2006; 60:760-6.

11. American Psychiatric Association. Diagnostic and statistical manual of mental disorders: DSM-5. 5th edn. Washingron, DC: American Psychiatric Association; 2013.

12. Davis M, Walker DL, Miles L, Grillon C. Phasic vs sustained fear in rats and humans: role of the extended amygdala in fear vs. anxiety. Neuropsychopharmacol 2010;35:105-35.

13. Barlow $\mathrm{DH}$. Anxiety and its disorders: the nature and treatment of anxiety and panic. New York: Guilford Press; 1988.

14. Mineka S, Zinbarg R. Conditioning and ethological models of anxiety disorders: stress-in-dynamic-context anxiety models. In: Hope DA, editor. Perspective on Anxiety, Panic, \& Fear. Lincoln and London: University of Nebraska Press; 1996. pp. 135-210.

15. Schmitz A, Grillon C. Assessing fear and anxiety in humans using threat of predictable and unpredictable aversive events (the NPU-threat test). Nat Protoc 2012;7:527-32.

16. Kirschbaum C, Pirke KM, Hellhammer DH. The 'Trier Social Stress Test'-a tool for investigating psychobiological stress responses in a laboratory setting. Neuropsychobiology 1993;28:76-81.

17. Dedovic K, Renwick R, Mahani NK, Engert V, Lupien SJ, Pruessner JC. The Montreal Imaging Stress Task: using functional imaging to investigate the effects of perceiving and processing psychosocial stress in the human brain. J Psychiatry Neurosci 2005;30:318-25.

18. Kogler L, Müller VI, Chang A, Eickhoff SB, Fox PT, Gur RC, et al. Psychosocial versus physiological stress-meta-analyses on deactivations and activations of the neural correlates of stress reactions. Neurolmage 2015; 119:235-51.

19. Blumenthal TD, Chapman JG, Muse KB. Effects of social anxiety, attention, and extraversion on the acoustic startle eyeblink response. Personal Individ Differ 1995;19:797-807.
20. Vytal K, Cornwell B, Arkin N, Grillon C. Describing the interplay between anxiety and cognition: from impaired performance under low cognitive load to reduced anxiety under high load. Psychophysiology 2012;49:842-52.

21. Robinson OJ, Bond RL, Roisier JP. The impact of threat of shock on the framing effect and temporal discounting: executive functions unperturbed by acute stress? Front Psychol 2015;6:1315.

22. Gillan CM, Vaghi MM, Hezemans FH, van Ghesel GS, Dafflon J, Brühl AB, et al. Experimentally-induced and real-world acute anxiety have no effect on goaldirected behaviour. bioRxiv. 2019:606145

23. Bailey JE, Papadopoulos A, Lingford-Hughes A, Nutt DJ. D-Cycloserine and performance under different states of anxiety in healthy volunteers. Psychopharmacology 2007;193:579-85.

24. Garner M, Attwood A, Baldwin DS, James A, Munafò MR. Inhalation of $7.5 \%$ carbon dioxide increases threat processing in humans. Neuropsychopharmacol 2011;36:1557-62.

25. Garner M, Attwood A, Baldwin D, Munafò M. Inhalation of $7.5 \%$ carbon dioxide increases alerting and orienting attention network function. Psychopharmacology 2012;223:67-73.

26. Rollin MDH, Rollin BE. Crazy like a fox: validity and ethics of animal models of human psychiatric disease. Camb Q Health Ethics 2014;23:140-51.

27. Kaiser T, Feng G. Modeling psychiatric disorders for developing effective treatments. Nat Med 2015;21:979.

28. Santos M, D'Amico D, Dierssen M. From neural to genetic substrates of panic disorder: insights from human and mouse studies. Eur J Pharmacol. 2015;759:127-41.

29. Bueters T, Ploeger BA, Visser SAG. The virtue of translational PKPD modeling in drug discovery: selecting the right clinical candidate while sparing animal lives. Drug Discov Today 2013;18:853-62.

30. Dawson GR, Goodwin G. Experimental medicine in psychiatry. J Psychopharmacol 2005;19:565-6.

31. Griebel G, Holmes A. 50 years of hurdles and hope in anxiolytic drug discovery. Nat Rev Drug Discov 2013;12:667-87.

32. Rodgers RJ. Animal models of 'anxiety': where next? Behav Pharmacol 1997;8:477-96.

33. MacLean EL. Unraveling the evolution of uniquely human cognition. Proc Natl Acad Sci USA 2016;113:6348-54.

34. Pringle A, Harmer CJ. The effects of drugs on human models of emotional processing: an account of antidepressant drug treatment. Dialog- Clin Neurosci 2015;17:477-87.

35. Grillon C, Hale E, Lieberman L, Davis A, Pine DS, Ernst M. The CRH1 antagonist GSK561679 increases human fear but not anxiety as assessed by startle. Neuropsychopharmacol 2015;40:1064-71.

36. Bailey J, Papadopoulos A, Diaper A, Phillips S, Schmidt M, van der Ark P, et al. Preliminary evidence of anxiolytic effects of the $\operatorname{CRF}(1)$ receptor antagonist $\mathrm{R} 317573$ in the7.5\% $\mathrm{CO}(2)$ proof-of-concept experimental model of human anxiety. J Psychopharmacol 2011;25:1199-206.

37. Pine DS. Clinical advances from a computational approach to anxiety. Biol Psychiatry 2017;82:385-7.

38. Montoya A, Bruins R, Katzman MA, Blier P. The noradrenergic paradox: implications in the management of depression and anxiety. Neuropsychiatr Dis Treat 2016;12:541-57.

39. Harmer CJ, Cowen PJ 'It's the way that you look at it'-a cognitive neuropsychological account of SSRI action in depression. Philos Trans R Soc B. 2013;368:20120407. https://doi.org/10.1098/rstb.2012.0407.

40. Balderston NL, Roberts $C$, Masi E, Deng Z-D, Radman T, Luber B, et al. A causal link between right dIPFC Activity and anxiety expression revealed using repetitive transcranial magnetic stimulation. in 2019 Annual meeting of the Society of Biological Psychiatry, Chicago, 2019.

41. Pine DS, Helfinstein SM, Bar Haim Y, Nelson E, Fox NA. Challenges in developing novel treatments for childhood disorders: lessons from research on anxiety. Neuropsychopharmacol 2008;34:213-28.

42. Forsyth JP, Zvolensky MJ. Experimental psychopathology, clinical science, and practice: an irrelevant or indispensable alliance? Appl Prev Psychol 2001;10:243-64

43. Vervliet B, Raes F. Criteria of validity in experimental psychopathology: application to models of anxiety and depression. Psychol Med 2012;43:2241-4.

44. Kotov R, Krueger RF, Watson D, Achenbach TM, Althoff RR, Bagby RM, et al. The Hierarchical Taxonomy of Psychopathology (HiTOP): a dimensional alternative to traditional nosologies. J Abnorm Psychol 2017;126:454-77.

45. Insel T, Cuthbert B, Garvey M, Heinssen R, Pine DS, Quinn K, et al. Research Domain Criteria (RDoC): toward a new classification framework for research on mental disorders. Am J Psychiat 2010;167:748-51.

46. Bjelland I, Lie SA, Dahl AA, Mykletun A, Stordal E, Kraemer HC. A dimensional versus a categorical approach to diagnosis: Anxiety and depression in the HUNT 2 study. Int J Methods Psychiatr Res. 2009;18:128-37. 
47. Watson D, Gamez W, Simms LJ. Basic dimensions of temperament and their relation to anxiety and depression: a symptom-based perspective. J Res Pers 2005;39:46-66.

48. Calhoon GG, Tye KM. Resolving the neural circuits of anxiety. Nat Neurosci 2015;18:1394-404.

49. Robinson OJ, Krimsky M, Grillon C. The impact of induced anxiety on response inhibition. Front Hum Neurosci 2013;7:69.

50. Costello CG. Two dimensional views of psychopathology. Behav Res Ther 1994;32:391-402.

51. Greco JA, Liberzon I. Neuroimaging of fear-associated learning. Neuropsychopharmacology 2016;41:320-34.

52. Benkelfat C, Bradwejn J, Meyer E, Ellenbogen M, Milot S, Gjedde A, et al. Functional neuroanatomy of CCK4-induced anxiety in normal healthy volunteers. Am J Psychiatry 1995;152:1180-4.

53. Eser D, Leicht G, Lutz J, Wenninger S, Kirsch V, Schule $C$, et al. Functional neuroanatomy of CCK-4-induced panic attacks in healthy volunteers. Hum Brain Mapp 2009;30:511-22.

54. Bailey JE, Dawson GR, Dourish CT, Nutt DJ. Validating the inhalation of $7.5 \% \mathrm{CO} 2$ in healthy volunteers as a human experimental medicine: a model of generalized anxiety disorder (GAD). J Psychopharmacol 2011;25:1192-8.

55. Roberson-Nay R, Gorlin El, Beadel JR, Cash T, Vrana S, Teachman BA. Temporal stability of multiple response systems to $7.5 \%$ carbon dioxide challenge. Biol Psychol 2017;124:111-8.

56. Papadopoulos A, Rich A, Nutt D, Bailey J. The effects of single dose anxiolytic medication on the $\mathrm{CO} 2$ models of anxiety: differentiation of subjective and objective measures. J Psychopharmacol 2010;24:649-56.

57. Bailey JE, Papadopoulos A, Seddon K, Nutt DJ. A comparison of the effects of a subtype selective and non-selective benzodiazepine receptor agonist in two $\mathrm{CO} 2$ models of experimental human anxiety. J Psychopharmacol 2008;23:117-22.

58. Bailey JE, Argyropoulos SV, Kendrick AH, Nutt DJ. Behavioral and cardiovascular effects of 7.5\% CO2 in human volunteers. Depress Anxiety 2005:21:18-25.

59. Bailey JE, Kendrick A, Diaper A, Potokar J, Nutt DJ. A validation of the $7.5 \% \mathrm{CO} 2$ model of GAD using paroxetine and lorazepam in healthy volunteers. J Psychopharmacol 2007;21:42-49.

60. Grillon C, Pellowski M, Merikangas KR, Davis M. Darkness facilitates the acoustic startle in humans. Biol Psychiatry 1997;42:453-60.

61. Grillon C, Morgan CA, Davis M, Southwick SM. Effect of darkness on acoustic startle in Vietnam veterans with PTSD. Am J Psychiatry 1998;155:812-7.

62. Kamkwalala A, Norrholm SD, Poole JM, Brown A, Donley S, Duncan E, et al. Darkenhanced startle responses and heart rate variability in a traumatized civilian sample: putative sex-specific correlates of posttraumatic stress disorder. Psychosom Med 2012;74:153-9.

63. Grillon C, Ameli R, Woods SW, Merikangas K, Davis M. Fear-potentiated startle in humans: effects of anticipatory anxiety on the acoustic blink reflex. Psychophysiology 1991;28:588-95.

64. Shankman SA, Robison-Andrew EJ, Nelson BD, Altman SE, Campbell ML. Effects of predictability of shock timing and intensity on aversive responses. Int J Psychophysiol 2011;80:112-8.

65. Seddon K, Morris K, Bailey J, Potokar J, Rich A, Wilson S, et al. Effects of 7.5\% CO2 challenge in generalized anxiety disorder. J Psychopharmacol 2011;25:43-51.

66. Grillon C, Pine DS, Lissek S, Rabin S, Bonne O, Vythilingam M. Increased anxiety during anticipation of unpredictable aversive stimuli in posttraumatic stress disorder but not in generalized anxiety disorder. Biol Psychiatry 2009;66:47-53.

67. Grillon C, Lissek S, Rabin S, McDowell D, Dvir S, Pine DS. Increased anxiety during anticipation of unpredictable but not predictable aversive stimuli as a psychophysiologic marker of panic disorder. Am J Psychiatry 2008;165:898-904.

68. Gorka S, Liu H, Sarapas C, Shankman S. Time course of threat responding in panic disorder and depression. Int J Psychophysiol 2015;98:87-94.

69. Gorka SM, Nelson BD, Shankman SA. Startle response to unpredictable threat in comorbid panic disorder and alcohol dependence. Drug Alcohol Depend 2013;132:216-22.

70. Gorka SM, Hee D, Lieberman L, Mittal VA, Phan KL, Shankman SA. Reactivity to uncertain threat as a familial vulnerability factor for alcohol use disorder. Psychol Med 2016;46:1-10.

71. Gorka SM, Lieberman L, Phan KL, Shankman SA. Startle potentiation to uncertain threat as a psychophysiological indicator of fear-based psychopathology: an examination across multiple internalizing disorders. J Abnorm Psychol. 2017;126:8-18.

72. Moberg CA, Bradford DE, Kaye JT, Curtin JJ. Increased startle potentiation to unpredictable stressors in alcohol dependence: possible stress neuroadaptation in humans. J Abnorm Psychol 2017;126:441-53.

73. Figel B, Brinkmann L, Buff C, Heitmann CY, Hofmann D, Bruchmann M, et al. Phasic amygdala and BNST activation during the anticipation of temporally unpredictable social observation in social anxiety disorder patients. NeuroImage: Clin 2019;22:101735.
74. Buff C, Brinkmann L, Bruchmann M, Becker MPI, Tupak S, Herrmann MJ, et al. Activity alterations in the bed nucleus of the stria terminalis and amygdala during threat anticipation in generalized anxiety disorder. Soc Cogn Affect Neurosci 2017; 12:1766-74.

75. Brinkmann L, Buff C, Neumeister P, Tupak SV, Becker MPI, Herrmann MJ, et al. Dissociation between amygdala and bed nucleus of the stria terminalis during threat anticipation in female post-traumatic stress disorder patients. Hum Brain Mapp 2017;38:2190-205.

76. Brinkmann L, Buff C, Feldker K, Tupak SV, Becker MPI, Herrmann MJ, et al. Distinct phasic and sustained brain responses and connectivity of amygdala and bed nucleus of the stria terminalis during threat anticipation in panic disorder. Psychol Med 2017;47:1-14.

77. Herrmann MJ, Boehme S, Becker MPI, Tupak SV, Guhn A, Schmidt B, et al. Phasic and sustained brain responses in the amygdala and the bed nucleus of the stria terminalis during threat anticipation. Hum Brain Mapp 2016;37:1091-102.

78. Alvarez R, Lissek S, Biggs A, Grillon C. Contextual fear conditioning in a virtual reality environment: a fMRI study. in The Organization for Human Brain Mapping, Chicago, II 2007.

79. Alvarez RP, Biggs A, Chen G, Pine DS, Grillon C. Contextual fear conditioning in humans: cortical-hippocampal and amygdala contributions. J Neurosci 2008;28:6211-9.

80. Alvarez RP, Chen G, Bodurka J, Kaplan R, Grillon C. Phasic and sustained fear in humans elicits distinct patterns of brain activity. Neuroimage 2011;1:389-400.

81. McMenamin BW, Langeslag SJE, Sirbu M, Padmala S, Pessoa L. Network organization unfolds over time during periods of anxious anticipation. J Neurosci 2014:34:11261-73.

82. McMenamin BW, Pessoa L. Discovering networks altered by potential threat ("anxiety") using quadratic discriminant analysis. Neurolmage 2015;116:1-9.

83. Bijsterbosch J, Smith S, Bishop SJ. Functional connectivity under anticipation of shock: correlates of trait anxious affect versus induced anxiety. J Cogn Neurosci 2015:27:1-14.

84. Pessoa L. A network model of the emotional brain. Trends Cogn Sci 2017;21:357-71.

85. Baars BJ, Franklin S. How conscious experience and working memory interact. Trends Cogn Sci 2003;7:166-72.

86. Mathews A, Mackintosh BA. A cognitive model of selective processing in anxiety. Cogn Ther Res 1998;22:539-60.

87. Eysenck MW, Derakshan N, Santos R, Calvo MG. Anxiety and cognitive performance: attentional control theory. Emotion 2007;7:336-53.

88. Kopp CB. Antecedents of self-regulation: a developmental perspective. Dev Psychol 1982;18:199-214.

89. Hofmann W, Schmeichel BJ, Baddeley AD. Executive functions and selfregulation. Trends Cogn Sci 2012;16:174-80.

90. Hartley CA, Phelps EA. Anxiety and decision-making. Biol Psychiatry 2012;72:113-8.

91. Derryberry D, Reed MA. Anxiety-related attentional biases and their regulation by attentional control. J Abnorm Psychol 2002;111:225-36.

92. Bar-Haim Y, Lamy D, Pergamin L, Bakermans-Kranenburg MJ, van IMH. Threatrelated attentional bias in anxious and nonanxious individuals: a meta-analytic study. Psychol Bull 2007;133:1-24.

93. Bishop SJ. Trait anxiety and impoverished prefrontal control of attention. Nat Neurosci 2009;12:92-98.

94. Walters E, Carew T, Kandel E. Associative Learning in Aplysia: evidence for conditioned fear in an invertebrate. Science 1981;211:504-6.

95. Davis $M$. The role of the amygdala in fear-potentiated startle: implication for animal models of anxiety. Trends Pharmacol Sci 1992;13:35-41.

96. Kuhn M, Wendt J, Sjouwerman R, Büchel C, Hamm A, Lonsdorf TB. The neurofunctional basis of affective startle modulation in humans-evidence from combined facial EMG-fMRI. bioRxiv. 2019:567032

97. Beck AT, Clark DA. An information processing model of anxiety: automatic and strategic processes. Behav Res Ther 1997;35:49-58.

98. Robinson OJ, Lieberman L, Allen P, Vytal K, Grillon C. The dorsal medial prefrontal-amygdala 'aversive amplification' circuit in unmedicated generalized and social anxiety disorders. Lancet Psychiatry 2014;1:294-302.

99. Borkovec TD, Alcaine OM, Behar E. Avoidance theory of worry and generalized anxiety disorder. In: Heimberg RG, Turk CL, Mennin DS, editors. Generalized anxiety disorder: advances in research and practice. New York: Guilford; 2004. pp. 77-108.

100. Morris LW, Liebert RM. Effects of negative feedback, threat of shock, and level of trait anxiety on the arousal of two components of anxiety. J Couns Psychol 1973;20:321-6.

101. Mennin DS, Heimberg RG, Turk CL, Fresco DM. Applying an emotion regulation framework to integrative approaches to generalized anxiety disorder. Clin Psychol: Sci Pract 2002;9:85-90.

102. Kagan J, Reznick JS, Snidman N. Biological basis of childhood shyness. Science 1988;240:167-71. 
103. Dymond S. Overcoming avoidance in anxiety disorders: the contributions of Pavlovian and operant avoidance extinction methods. Neurosci Biobehav Rev. 2019;98:61-70

104. Cornwell BR, Garrido MI, Overstreet C, Pine DS, Grillon C. The un-predictive brain under threat: a neuro-computational account of anxious hypervigilance. Biol Psychiatry 2017;82:447-54.

105. Cornwell BR, Baas JMP, Johnson L, Holroyd T, Carver FW, Lissek S, et al. Neural responses to auditory stimulus deviance under threat of electric shock revealed by spatially-filtered magnetoencephalography. Neuroimage 2007; 37:282-9.

106. Weinberg A, Klein DN, Hajcak G. Increased error-related brain activity distinguishes generalized anxiety disorder with and without comorbid major depressive disorder. J Abnorm Psychol 2012;121:885-96.

107. Criteria NAMHCWoTaMfRD: Behavioral Assessment Methods for RDoC Constructs. in A Report by the National Advisory Mental Health Council Workgroup on Tasks and Measures for Research Domain Criteria (RDoC), Bethesda, MD, Z:/ PDF 3/Anxiety-disorders/RDoC; 2016. pp. pp. 163.

108. Green MF, Nuechterlein KH, Gold JM, Barch DM, Cohen J, Essock S, et al. Approaching a consensus cognitive battery for clinical trials in schizophrenia: the NIMH-MATRICS conference to select cognitive domains and test criteria. Biol Psychiatry 2004;56:301-7.

109. Brovelli A, Ding M, Ledberg A, Chen $Y$, Nakamura R, Bressler SL. Beta oscillations in a large-scale sensorimotor cortical network: directional influences revealed by Granger causality. Proc Natl Acad Sci USA 2004;101:9849-54.

110. Friston KJ, Harrison L, Penny W. Dynamic causal modelling. Neurolmage 2003;19:1273-302.

111. Friston K, Moran R, Seth AK. Analysing connectivity with Granger causality and dynamic causal modelling. Curr Opin Neurobiol 2013;23:172-8.

112. Robinson OJ, Chase HW. Learning and choice in mood disorders: searching for the computational parameters of anhedonia. Comput Psychiatr 2017;1:208-33.

113. Charpentier CJ, Hindocha C, Roiser JP, Robinson OJ. Anxiety promotes memory for mood-congruent faces but does not alter loss aversion. Sci Rep 2016; 6:24746.

114. Sussman TJ, Szekely A, Hajcak G, Mohanty A. It's all in the anticipation: how perception of threat is enhanced in anxiety. Emotion 2016;16:320-7.

115. Weymar M, Bradley MM, Hamm AO, Lang PJ. Encoding and reinstatement of threat: recognition potentials. Neurobiol Learn Mem 2014;107:87-92.

116. Yang $Y$, Miskovich TA, Larson CL. State pnxiety impairs proactive but enhances reactive control. Front Psychol 2018;9:2570.

117. Clarke RJ, Johnstone T. Prefrontal inhibition of threat processing reduces working memory interference. Front Hum Neurosci. 2013;7:228. https://doi.org/ 10.3389/fnhum.2013.00228.

118. Pessoa L, Padmala S, Kenzer A, Bauer A. Interactions between cognition and emotion during response inhibition. Emotion 2012;12:192-7.

119. Choi J, Padmala S, Pessoa L. Impact of state anxiety on the interaction between threat monitoring and cognition. Neuroimage 2012;59:1912-23.

120. Robinson OJ, Vytal K, Cornwell BR, Grillon C. The impact of anxiety upon cognition: perspectives from human threat of shock studies. Front Hum Neurosci 2013;7:203.

121. Cooper R, Howard CJ, Attwood AS, Stirland R, Rostant V, Renton L, et al. Acutely induced anxiety increases negative interpretations of events in a closed-circuit television monitoring task. Cogn Emot 2013;27:273-82.

122. Shin LM, Liberzon I. The neurocircuitry of fear, stress, and anxiety disorders. Neuropsychopharmacology. 2010;35:169-191. https://doi.org/10.1038/npp.2009.83.

123. Forster $\mathrm{GL}$, Simons RL, Baugh LA: Revisiting the role of the amygdala in posttraumatic stress disorder. In: B. Ferry editor. The amygdala: Where emotions shape perception, learning and memories. London: InTech; 2017. pp. 113-36. https://doi.org/10.5772/67585.

124. Lang PJ, McTeague LM, Bradley MMRDoC. DSM, and the reflex physiology of fear: a biodimensional analysis of the anxiety disorders spectrum. Psychophysiology 2016;53:336-47.

125. Bradford DE, Shapiro BL, Curtin JJ. How bad could It be? Alcohol dampens stress responses to threat of uncertain intensity. Psychol Sci 2013;24:2541-9.

126. Pringle A, Warren M, Gottwald J, Cowen PJ, Harmer CJ. Cognitive mechanisms of diazepam administration: a healthy volunteer model of emotional processing. Psychopharmacology 2016;233:2221-8.

127. Murphy SE, Yiend J, Lester KJ, Cowen PJ, Harmer CJ. Short-term serotonergic but not noradrenergic antidepressant administration reduces attentional vigilance to threat in healthy volunteers. Int J Neuropsychopharmacol 2009;12:169-79.

128. Valdez GR. Development of CRF1 receptor antagonists as antidepressants and anxiolytics: progress to date. CNS Drugs 2006;20:887-96.

129. Risbrough VB, Stein MB. Role of corticotropin releasing factor in anxiety disorders: a translational research perspective. Horm Behav 2006;50:550-61.

130. Walker D, Yang Y, Ratti E, Corsi M, Trist D, Davis M. Differential effects of the CRFR1 antagonist GSK876008 on fear-potentiated, light- and CRF-enhanced startle suggest preferential involvement in sustained vs phasic threat responses. Neuropsychopharmacol 2009:34:1533-42.

131. Griebel G, Holsboer F. Neuropeptide receptor ligands as drugs for psychiatric diseases: the end of the beginning? Nat Rev Drug Discov 2012;11:462-78.

132. Schwandt ML, Cortes CR, Kwako LE, George DT, Momenan R, Sinha R, et al. The CRF1 antagonist verucerfont in anxious alcohol-dependent women: translation of neuroendocrine, but not of anti-craving effects. Neuropsychopharmacology 2016;41:2818-29.

133. Dunlop BW, Binder EB, losifescu D, Mathew SJ, Neylan TC, Pape JC, et al Corticotropin-releasing factor type 1 receptor antagonism is ineffective for women with posttraumatic stress disorder. Biol Psychiatry 2017;82:866-74.

134. Lago TR, Hsiung A, Leitner BP, Duckworth CJ, Balderston NL, Chen $K Y$, et al. Exercise modulates the interaction between cognition and anxiety in humans. Cogn Emot. 2019;33:863-70. https://doi.org/10.1080/02699931.2018.1500445.

135. Gorka SM, Lieberman L, Klumpp H, Kinney KL, Kennedy AE, Ajilore O, et al. Reactivity to unpredictable threat as a treatment target for fear-based anxiety disorders. Psychol Med 2017;47:1-11.

136. Costello CG. Anxiety and the persisting novelty of input from the autonomic nervous system. Behav Ther 1971;2:321-33.

137. Gray JA. The psychology of fear and stress. Cambridge: Cambridge University Press; 1987.

138. Ludewig S, Geyer MA, Ramseier M, Vollenweider FX, Rechsteiner E, CattapanLudewig K. Information-processing deficits and cognitive dysfunction in panic disorder. J Psychiatry Neurosci 2005;30:37-43.

139. Ludewig S, Ludewig K, Geyer MA, Hell D, Vollenweider FX. Prepulse inhibition deficits in patients with panic disorder. Depress Anxiety 2002;15:55-60.

140. Morgan CA III, Grillon C. Abnormal mismatch negativity in women with sexual assault-related posttraumatic stress disorder. Biol Psychiatry 1999; 45:827-32.

141. Ge Y, Wu J, Sun $X$, Zhang K. Enhanced mismatch negativity in adolescents with posttraumatic stress disorder (PTSD). Int J Psychophysiol 2011;79:231-5.

142. Chang $Y, X u$ J, Pang $X$, Sun $Y$, Zheng $Y$, Liu $Y$. Mismatch negativity indices of enhanced preattentive automatic processing in panic disorder as measured by a multi-feature paradigm. Biol Psychol 2015;105:77-82.

143. Wessel JR, Aron AR. On the globality of motor suppression: unexpected events and their influence on behavior and cognition. Neuron 2017;93:259-80.

144. Näätänen R, Kujala T, Winkler I. Auditory processing that leads to conscious perception: a unique window to central auditory processing opened by the mismatch negativity and related responses. Psychophysiology 2011;48:4-22.

145. Näätänen $R$, Paavilainen $P$, Titinen $H$, Jiang $D$, Alho $K$. Attention and mismatch negativity. Psychophysiology 1993;30:436-50.

146. Fan L, Sun Y-B, Sun Z-K, Wang N, Luo F, Yu F, et al. Modulation of auditory sensory memory by chronic clinical pain and acute experimental pain: a mismatch negativity study. Sci Rep 2018;8:15673.

147. Gené-Cos N, Ring HA, Pottinger RC, Barrett G. Possible roles for mismatch negativity in neuropsychiatry. Cogn Behav Neurol 1999;12:17-27.

148. Mager R, Bullinger AH, Mueller-Spahn F, Kuntze MF, Stoermer R. Real-time monitoring of brain activityin patients with specific phobia during exposure therapy, employing a stereoscopi virtual environment. Cyber Behav 2001; 4:465-9.

149. Marshall PJ, Reeb BC, Fox NA. Electrophysiological responses to auditory novelty in temperamentally different 9-month-old infants. Dev Sci 2009;12:568-82.

150. Giard $\mathrm{MH}$, Perrin F, Pernier J, Bouchet P. Brain generators implicated in the processing of auditory stimulus deviance: a topographic event-related potential study. Psychophysiology 1990;27:6627-40.

151. Garrido MI, Kilner JM, Stephan KE, Friston KJ. The mismatch negativity: a review of underlying mechanisms. Clin Neurophysiol 2009;120:453-63.

152. Davis M. The role of the amygdala in fear and anxiety. Annu Rev Neurosci 1992;15:353-75.

153. Vuilleumier P. How brains beware: neural mechanisms of emotional attention. Trends Cogn Sci 2005;9:585-94.

154. Wessel JR, Danielmeier C, Morton JB, Ullsperger M. Surprise and error: common neuronal architecture for the processing of errors and novelty. J Neurosci 2012;32:7528-37.

155. Ousdal OT, Andreassen OA, Server A, Jensen J. Increased amygdala and visual cortex activity and functional connectivity towards stimulus novelty is associated with state anxiety. PLoS ONE 2014;9:e96146.

156. D'Hulst C, Atack JR, Kooy RF. The complexity of the GABAA receptor shapes unique pharmacological profiles. Drug Discov Today. 2009;14:866-75.

157. Pellow S, File SE. Multiple sites of action for anxiogenic drugs: behavioural, electrophysiological and biochemical correlations. Psychopharmacol 1984;83: 304-15.

158. Smolnik R, Pietrowsky $\mathrm{R}$, Fehm HL, Born J. Enhanced selective attention after low-dose administration of the benzodiazepine antagonist flumazenil. J Clin Psychopharmacol 1998;18:241-7. 
159. Nakagome K, Ichikawa I, Kanno O, Akaho R, Suzuki M, Takazawa S, et al. Overnight effects of triazolam on cognitive function: an event-related potentials study. Neuropsychobiology 1998;38:232-40.

160. Rosburg T, Marinou V, Haueisen J, Smesny S, Sauer H. Effects of lorazepam on the neuromagnetic mismatch negativity $(\mathrm{MMNm})$ and auditory evoked field component N100m. Neuropsychopharmacology 2004;29:1723-33.

161. Grillon C, Charney DR. In the face of fear: anxiety sensitizes defensive responses to fearful faces. Psychophysiology 2011;12:1745-52.

162. Morris JS, DeGelder B, Weiskrantz L, Dolan RJ. Differential extrageniculostriate and amygdala responses to presentation of emotional faces in a cortically blind field. Brain 2001;124:1241-52.

163. Whalen PJ, Rauch SL, Etcoff NL, Mclnerney SC, Lee MB, Jenike MA. Masked presentations of emotional facial expressions modulate amygdala activity without explicit knowledge. J Neurosci 1998;18:411-8.

164. Bishop S, Duncan J, Brett M, Lawrence AD. Prefrontal cortical function and anxiety: controlling attention to threat-related stimuli. Nat Neurosci 2004;7:184-8.

165. Dolcos F, McCarthy G. Brain systems mediating cognitive interference by emotional distraction. J Neurosci 2006;26:2072-9.

166. MacDonald AW, Cohen JD, Stenger VA, Carter CS. Dissociating the role of the dorsolateral prefrontal and anterior cingulate cortex in cognitive control. Science 2000;288:1835-8.

167. Robinson OJ, Letkiewicz AM, Overstreet C, Ernst M, Grillon C. The effect of induced anxiety on cognition: threat of shock enhances aversive processing in healthy individuals. Cogn Affect Behav Neurosci 2011;11:217-27.

168. Robinson OJ, Charney DR, Overstreet C, Vytal K, Grillon C. The adaptive threat bias in anxiety: amygdala-dorsomedial prefrontal cortex coupling and aversive amplification. Neuroimage 2012;60:523-9.

169. Etkin A, Egner T, Kalisch R. Emotional processing in anterior cingulate and medial prefrontal cortex. Trends Cogn Sci 2011;15:85-93.

170. Vytal K, Overstreet C, Charney D, Robinson OJ, Grillon C. Sustained anxiety increases amygdala-dorsomedial prefrontal coupling: a mechanism for maintaining an anxious state. J Psychiatry Neurosci 2014;39:321-9.

171. Robinson OJ, Krimsky M, Lieberman L, Vytal K, Ernst M, Grillon C. Anxietypotentiated amygdala-medial frontal coupling and attentional control. Transl Psychiatry 2016;6:e833.

172. Robinson OJ, Cools R, Crockett MJ, Sahakian BJ. Mood state moderates the role of serotonin in cognitive biases. J Psychopharmacol 2010;24:573-83.

173. Harmer CJ. Serotonin and emotional processing: does it help explain antidepressant drug action? Neuropharmacology 2008;55:1023-8.

174. Nutt DJ. The neuropharmacology of serotonin and noradrenaline in depression. Int Clin Psychopharmacol 2002;17 (Suppl. 1):S1-S12.

175. Hariri AR, Mattay VS, Tessitore A, Kolachana B, Fera F, Goldman D, et al. Serotonin transporter genetic variation and the response of the human amygdala. Science 2002;297:400-3.

176. Robinson OJ, Overstreet $C$, Allen PS, Letkiewicz A, Vytal K, Pine DS, et al. The role of serotonin in the neurocircuitry of negative affective bias: serotonergic modulation of the dorsal medial prefrontal-amygdala 'aversive amplification' circuit. Neuroimage 2013;78:217-23.

177. Walsh AEL, Harmer CJ. The cognitive neuropsychological model of antidepressant response. Curr Opin Psychol 2015;4:124-30.
178. Butler AC, Chapman JE, Forman EM, Beck AT. The empirical status of cognitivebehavioral therapy: a review of meta-analyses. Clin Psychol Rev. 2006;26:17-31.

179. McLean CP, Asnaani A, Litz BT, Hofmann SG. Gender differences in anxiety disorders: prevalence, course of illness, comorbidity and burden of illness. J Psychiatr Res 2011;45:1027-35.

180. Patel N, Vytal K, Pavletic N, Stoodley C, Pine DS, Grillon C, et al. Interaction of threat and verbal working-memory in adolescents. Psychophysiology 2016;53:518-26.

181. Lieberman LC, Gorka SM, Sarapas C, Shankman SA. Cognitive flexibility mediates the relation between intolerance of uncertainty and safety signal responding in those with panic disorder. Cogn Emot 2015;30:1495-503.

182. Gorka SM, Lieberman L, Nelson BD, Sarapas C, Shankman SA. Aversive responding to safety signals in panic disorder: the moderating role of intolerance of uncertainty. J Anxiety Disord 2014;28:731-6.

183. Roberson-Nay R, Beadel JR, Gorlin El, Latendresse SJ, Teachman BA. Examining the latent class structure of $\mathrm{CO} 2$ hypersensitivity using time course trajectories of panic response systems. J Behav Ther Exp Psychiatry 2015;47:68-76.

184. Nay WT, Thorpe GL, Roberson-Nay R, Hecker JE, Sigmon ST. Attentional bias to threat and emotional response to biological challenge. J Anxiety Disord 2004;18:609-27.

185. Kane MJ, Engle RW. The role of prefrontal cortex in working-memory capacity, executive attention, and general fluid intelligence: An individual-differences perspective. Psychon Bull Rev. 2002;9:637-71.

186. Insel TR. Translating scientific opportunity into public health impact: a strategic plan for research on mental illness. Arch Gen Psychiatry 2009;66:128-33.

187. Blanchard RJ, Blanchard DC. Anti-predator defense as models of fear and anxiety. In: Brain PF, Blanchard RJ, Parmigiani S, editors. Fear and Defense. Amsterdam, Netherlands: Harwood Academic Publishers; 1990. pp. 89-108.

188. Blanchard RJ, McKittrick CR, Blanchard DC. Animal models of social stress: effects on behavior and brain neurochemical systems. Physiol Behav. 2001;73:261-71.

189. Kogler L, Müller VI, Chang A, Eickhoff SB, Fox PT, Gur RC, et al. Psychosocial versus physiological stress-meta-analyses on deactivations and activations of the neural correlates of stress reactions. Neurolmage 2015;119:235-51.

190. Kaye JT, Bradford DE, Curtin JJ. Psychometric properties of startle and corrugator response in NPU, affective picture viewing, and resting state tasks. Psychophysiology 2016;53:1241-55.

191. Baldwin DS, Hou R, Gordon R, Huneke NTM, Garner M. Pharmacotherapy in generalized anxiety disorder: novel experimental medicine nodels and emerging drug targets. CNS Drugs 2017;31:307-17.

192. Price M, Anderson PL. Latent growth curve analysis of fear during a speech task before and after treatment for social phobia. Behav Res Ther 2011;49:763-70.

193. Goldin PR, Manber T, Hakimi S, Canli T, Gross JJ. Neural bases of social anxiety disorder: emotional reactivity and cognitive regulation during social and physical threat. Arch Gen Psychiatry 2009;66:170-80.

194. Biedermann SV, Biedermann DG, Wenzlaff F, Kurjak T, Nouri S, Auer MK, et al. An elevated plus-maze in mixed reality for studying human anxiety-related behavior. BMC Biol 2017;15:125-125.

195. Iordan AD, Dolcos S, Dolcos F. Brain activity and network interactions in the impact of internal emotional distraction. Cereb Cortex 2018;29:1-17.

196. Balderston NL, Liu L, Roberson-Nay R, Ernst M, Grillon C. The relationship between dIPFC activity during unpredictable threat and $\mathrm{CO}$-induced panic symptoms. Transl Psychiatry 2017;7:1266. 